\title{
Heterobeltiosis in Banana and Genetic Gains through Crossbreeding ${ }^{\dagger}$
}

\author{
Michael Batte 1,2, Brigitte Uwimana 2, Rony Swennen 3, Allan Brown 3, \\ Helena Persson Hovmalm ${ }^{1}$, Mulatu Geleta ${ }^{1}$ and Rodomiro Ortiz 1,* \\ 1 Department of Plant Breeding, Swedish University of Agricultural Sciences, SE 23053 Alnarp, Sweden; \\ m.batte@cgiar.org (M.B.); helena.persson@slu.se (H.P.H.); mulatu.geleta.dida@slu.se (M.G.) \\ 2 International Institute of Tropical Agriculture, P.O. Box 7878, Kampala, Uganda; b.uwimana@cgiar.org \\ 3 International Institute of Tropical Agriculture, P.O. Box 447, Arusha, Tanzania; \\ rony.swennen@kuleuven.be (R.S.); a.brown@cgiar.org (A.B.) \\ * Correspondence: rodomiro.ortiz@slu.se \\ + Presented at the third International Tropical Agriculture Conference (TROPAG 2019), Brisbane, Australia, \\ 11-13 November 2019. \\ Publish: 8 April 2020
}

\begin{abstract}
Heterosis, or hybrid vigour, is the superiority of the hybrid for a certain trait over the mean of its two parents. Heterobeltiosis is a form of heterosis where the hybrid is superior to its best parent. Banana breeding is a tedious, time-consuming process, taking up to two decades to develop a hybrid. Understanding heterosis in banana breeding will contribute to selecting right breeding materials for further crossing, thus increasing banana breeding efficiency. Here we document heterobeltiosis by using the recently bred NARITA 'Matooke' hybrids and their ancestors. NARITA hybrids, their parents ( $4 x$ and $2 x$ ), grandparents ( $3 x$ and $2 x$ ), and local $3 x^{\prime}$ Matooke' cultivar checks were planted in a rectangular lattice design with two replications. Yield and other agronomic data were collected at flowering and harvest. The NARITAs were compared with their $3 x$ 'Matooke' grandmothers. Heterobeltiosis on bunch weight was calculated with the data of 3 cycles. All the NARITAs showed heterobeltiosis for bunch weight. NARITA 17 had the highest grandparent heterobeltiosis (ca. 250\%). Genetic gains due to crossbreeding were determined for fruit yield considering three generations: matooke cultigen $\left(\mathrm{C}_{0}\right)$, primary tetraploid hybrids $\left(\mathrm{C}_{1}\right)$ and secondary tetraploid hybrids $\left(C_{2}\right)$. The average genetic gain (from $C_{0}$ to $C_{2}$ ) rates for bunch weight $(\mathrm{kg})$ and yield potential $\left(\mathrm{t} \mathrm{ha}^{-1}\right.$ year $\left.^{-1}\right)$ were $1.4 \%$ and $1.3 \%$ per year, respectively.
\end{abstract}

Keywords: East Africa; fruit; heterosis; matooke; Musa; NARITA; selection cycles; yield potential

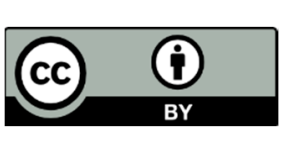

(C) 2020 by the authors. Licensee MDPI, Basel, Switzerland. This article is an open access article distributed under the terms and conditions of the Creative Commons Attribution (CC BY) license (http://creativecommons.org/licenses/by/4.0/). 